\title{
Nanoemulsions as Edible Coatings: A Potential Strategy for Fresh Fruits and Vegetables Preservation
}

\author{
Josemar Gonçalves de Oliveira Filho ${ }^{1}{ }^{\mathbb{C}}$, Marcela Miranda ${ }^{1}$ (), Marcos David Ferreira ${ }^{2, *}$ and Anne Plotto ${ }^{3, *}$ \\ 1 School of Pharmaceutical Sciences, São Paulo State University (UNESP), Rodovia Araraquara—Jaú Km 1, \\ Araraquara 14800-903, SP, Brazil; josemar.gooliver@gmail.com (J.G.d.O.F.); mmiranda.bio@gmail.com (M.M.) \\ 2 Embrapa Instrumentação, Rua XV de Novembro, 1452, São Carlos 13560-970, SP, Brazil \\ 3 ARS Horticultural Research Laboratory, United States Department of Agriculture, 2001 South Rock Road, \\ Fort Pierce, FL 34945, USA \\ * Correspondence: marcos.david@embrapa.br (M.D.F.); anne.plotto@usda.gov (A.P.)
}

check for updates

Citation: de Oliveira Filho, J.G.;

Miranda, M.; Ferreira, M.D.; Plotto, A. Nanoemulsions as Edible Coatings: A Potential Strategy for Fresh Fruits and Vegetables Preservation. Foods 2021, 10, 2438. https://doi.org/ $10.3390 /$ foods 10102438

Academic Editor: Like Mao

Received: 23 August 2021

Accepted: 6 October 2021

Published: 14 October 2021

Publisher's Note: MDPI stays neutral with regard to jurisdictional claims in published maps and institutional affiliations.

Copyright: (c) 2021 by the authors. Licensee MDPI, Basel, Switzerland This article is an open access article distributed under the terms and conditions of the Creative Commons Attribution (CC BY) license (https:// creativecommons.org/licenses/by/ $4.0 /)$.

\begin{abstract}
Fresh fruits and vegetables are perishable commodities requiring technologies to extend their postharvest shelf life. Edible coatings have been used as a strategy to preserve fresh fruits and vegetables in addition to cold storage and/or controlled atmosphere. In recent years, nanotechnology has emerged as a new strategy for improving coating properties. Coatings based on plant-source nanoemulsions in general have a better water barrier, and better mechanical, optical, and microstructural properties in comparison with coatings based on conventional emulsions. When antimicrobial and antioxidant compounds are incorporated into the coatings, nanocoatings enable the gradual and controlled release of those compounds over the food storage period better than conventional emulsions, hence increasing their bioactivity, extending shelf life, and improving nutritional produce quality. The main goal of this review is to update the available information on the use of nanoemulsions as coatings for preserving fresh fruits and vegetables, pointing to a prospective view and future applications.
\end{abstract}

Keywords: nanotechnology; wax coating; natural antimicrobials; essential oils; nanocoatings; post-harvest; bioactive compounds; quality; preservation methods; nanomaterials

\section{Introduction}

Fruits and vegetables are important sources of minerals, vitamins, and fibers, which are essential for human's well-being, and their consumption has been associated with several beneficial effects on human health. The demand for those benefits has considerably increased over the years due to consumer preference for natural products and changes in lifestyle [1]. In this sense, fruits and vegetables are an important component of the human diet.

After they are harvested, fruits and vegetables continue the respiration process, consuming $\mathrm{O}_{2}$ and releasing $\mathrm{CO}_{2}$ and water. Consequently, lipids, proteins, organic acids, and carbohydrates are metabolized and energy replacement is compromised, as the vegetable or fruit is separated from the mother plant [2]. Over time, quality characteristics such as color, flavor, weight, nutritional value, and bioactive compounds continue to deteriorate as a result of senescence [3]. The water released during the respiration process plays an important role in the postharvest quality of fresh fruits and vegetables and can result in loss of nutritional value, soft texture, sagging, wrinkling, and withering [4].

Although waxes were used to preserve citrus fruit in ancient China, it was not until the twentieth century that edible coatings based on emulsions were developed to preserve the quality of fresh fruits and vegetables [5]. These emulsions are typically formulated from oils (vegetable- or animal-derived), waxes (paraffin, carnauba wax, candelilla, or beeswax), and resins (shellac or wood rosin). Furthermore, polymer-based coating solutions can have additional functionality when formulated with plant essential oils having antimicrobial 
activity [6]. Due to their hydrophobic nature, oils and waxes have proven to be an efficient technology for fruits and vegetables preservation post-harvest, as they are able to minimize water loss and gas exchange and improve and/or preserve the physicochemical properties, such as color, firmness, fresh appearance, and microbial protection [7-10].

Recently, nanotechnology was introduced as a new tool for making coatings based on emulsions with improved properties and functionalities. Coatings are made of macro- or microemulsions (conventional) or nanoemulsions, for which the latter can be considered a conventional emulsion with very small particles. Droplets in nanoemulsions are on a nanoscale (particle radius less than $100 \mathrm{~nm}$ ) dispersed in an aqueous solution [11]. This changes the physical properties of the coating by further reducing moisture migration, gas exchange, oxidative reactions, and suppressing pathogenic growth (microorganisms), product deterioration and enhancing control of physiological disorders [12]. In addition, coatings based on nanoemulsions have shown to be promising vehicles for several active compounds, such as oil-soluble vitamins, antimicrobials, flavors, and nutraceuticals, which may further contribute to maintenance of food product quality attributes [13].

Figure 1 shows a survey of published scientific manuscripts on nanoemulsions as edible coatings for fruits and vegetables. The number of studies on the topic has increased considerably over the past few years, demonstrating the scientific community's increased interest in the topic. However, studies concerning in vivo biological efficiencies are limited [14] and applications on fruits and vegetables are even fewer. Thus, more research is essential to determine this technology's potential for future application on a commercial scale. In this context, the objective of this review is to update the available information on the use of nanoemulsions as coatings for preserving fresh fruits and vegetables.

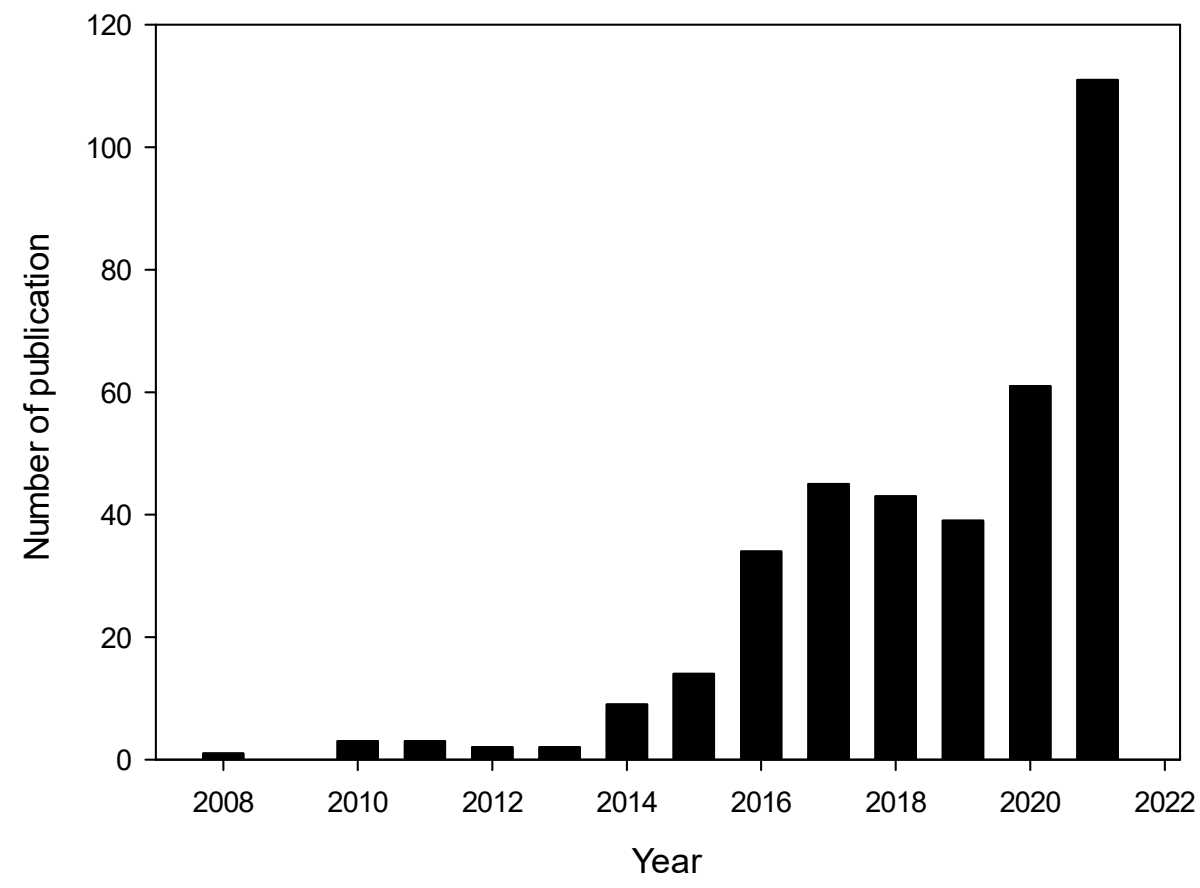

Figure 1. The distribution of publications related to 'nanoemulsion as edible coating for fruits and vegetables' (2005-2021): ScienceDirect databases. Data for 2021 is as of September 2021.

\section{Edible Coatings-An Overview}

The first reports of the use of coatings on fruits appeared in the 12th century in China, where wax was applied to citrus (lemons and oranges) to reduce mass loss and preserve the fruit [15]. However, it was only in 1922 that the commercial scale application of waxes began in order to increase postharvest conservation of fruits and vegetables, thus reducing postharvest losses [16]. 
Currently, edible coatings are used as a strategy to increase the shelf life and postharvest quality of many fresh fruits and vegetables during storage [17,18]. Edible coatings are defined as thin layers applied on the fruit surface, forming clear films produced from food-grade materials and adding to, or as a substitute for, the waxes naturally present on the fruit surface. As these films become part of the food and are consumed as such (for fruits where the peel is consumed), the materials used in their composition must be GRAS (Generally Recognized as Safe), that is, be non-toxic and safe for food [19].

Edible coatings are formulated from various biopolymers such as polysaccharide, lipid, and protein compounds, or by combining materials resulting in improved properties (Table 1). They act as an obstacle to water vapor, gases, and solutes [20] as shown in Figure 2.

Table 1. Summary of diverse structural materials frequently used for edible coating.

\begin{tabular}{|c|c|c|c|c|}
\hline Material & Main Matrices & Positive Points & Negative Points & References \\
\hline Polysaccharide & $\begin{array}{l}\text { Starch, chitosan, alginate, cellulose, and } \\
\text { its derivatives, and pectin }\end{array}$ & $\begin{array}{l}\text { Good gas and mechanical } \\
\text { barrier properties }\end{array}$ & $\begin{array}{l}\text { Poor moisture barrier due to } \\
\text { hydrophilic nature }\end{array}$ & {$[21,22]$} \\
\hline Lipid & $\begin{array}{l}\text { Animal, vegetable waxes and resins, } \\
\text { vegetable oil, and fatty acids }\end{array}$ & $\begin{array}{l}\text { Good moisture barrier properties } \\
\text { with a shiny appearance }\end{array}$ & $\begin{array}{l}\text { Poor mechanical and gas } \\
\text { barrier properties }\end{array}$ & {$[18,23,24]$} \\
\hline Protein & $\begin{array}{c}\text { Gelatin, casein, whey protein, zein, soy } \\
\text { protein, myofibrillar protein, and } \\
\text { quinoa protein }\end{array}$ & $\begin{array}{l}\text { Good gas barrier properties } \\
\text { without anaerobic conditions }\end{array}$ & $\begin{array}{l}\text { Brittle and susceptible } \\
\text { to cracking }\end{array}$ & [25] \\
\hline Composite & $\begin{array}{l}\text { Combination of polysaccharide and/or } \\
\text { protein with lipids }\end{array}$ & $\begin{array}{l}\text { Good moisture and gas } \\
\text { barrier properties }\end{array}$ & $\begin{array}{c}\text { Formation of } \\
\text { non-homogeneous emulsion }\end{array}$ & [26-29] \\
\hline
\end{tabular}

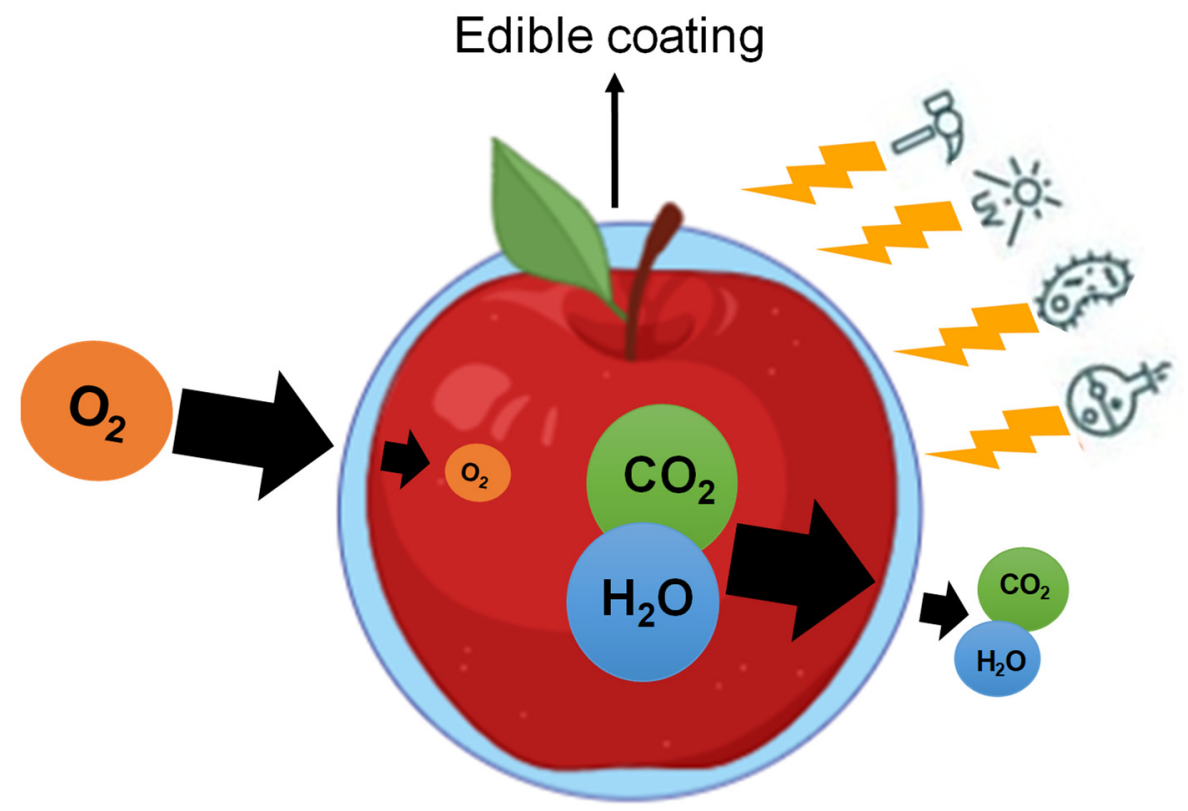

Figure 2. Main functions of edible coatings on fruits and vegetables.

The mechanism of action for coatings on fruit is similar to packaging with a modified atmosphere; the coating produces a physical barrier that modifies gas exchange between the interior of the fruit and the surrounding atmosphere, increasing the concentration of $\mathrm{CO}_{2}$ and decreasing $\mathrm{O}_{2}$ [30]. This environment can effectively decrease respiration rate, conserve stored energy, delay microbial growth, and therefore, extend the useful life of the fruit [31]. The coating efficiency depends on the coating thickness formed on the fruit surface, since there is a negative correlation between thickness and coating permeability [32]. Another important point is related to low permeability coatings, based on resins such as shellac, for example, which can restrict gas exchange almost entirely, leading to the accumulation of $\mathrm{CO}_{2}$ within the fruit, and the production of compounds 
resulting from the fermentation process that can cause off-flavor, such as acetaldehyde and ethanol, thus affecting fruit quality [18,33].

In addition to maintaining quality and postharvest conservation of fruits and vegetables, the coating materials can also act as carriers of compounds such as food coloring, flavoring, antimicrobials, antioxidants, antagonistic microorganisms, among others $[34,35]$. In this sense, several natural bioactive compounds have been incorporated into edible coating materials such as essential oils [36-38], plant extracts [39,40], vitamins [34], antagonistic microorganisms [41,42], and antibrowning or firming agents in fresh cut fruit. [43,44].

\section{Methods to Apply Edible Coatings}

The effectiveness of coatings in preserving fresh fruits and vegetables is influenced by the application method, which will be chosen according to the nature of the food to be coated, the surface attributes, the rheological properties of the solution, and the main purpose of the coating [45]. The adhesion of coatings to food surfaces is essential for performance of their intended function $[16,46]$. Wettability is used to quantify the interfacial interaction that occurs between the food surface and the coating. This variable must be taken into account when assessing the performance of the coating solution on the food surface [31].

Dipping (Figure 3a), spraying (Figure 3b), and hand coating (Figure 3c) techniques are the most common methods for applying edible coatings to fresh fruits and vegetables. Other techniques such as fluidized bed and foaming are also available; however, these techniques are rarely used on commercial and laboratory scales [45].

(a)

a)
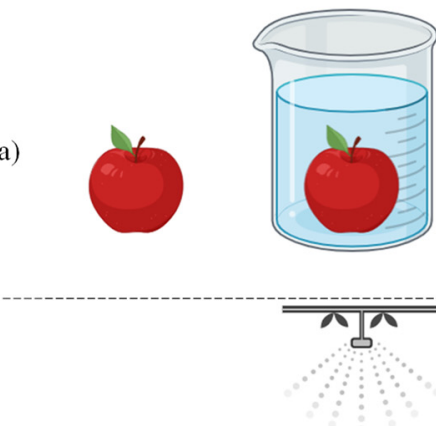

(b)

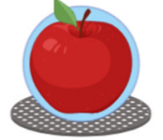

Advantages (A) / Disadvantage (D)

(A) Entire surface of the food comes into contact with the film-forming solution: complete wetting; Used to apply filmogenic solutions that have a wide viscosity range.

(D) Possibility of contamination of the coating solution; Use of large volumes of solution.

(A) Homogenic coating; Use of smaller volumes of solution; Avoids the possibility of contamination of the coating solution.

(D) Viscous solutions cannot be sprayed; tends to clog equipment.

(A) Use of smaller volumes of solution; It avoids the possibility of contamination of the coating solution.

(c)

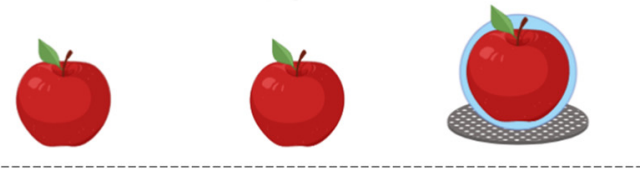

(D) Non-uniform coating thickness; non-continuous coating formation.

Figure 3. Dipping (a), spraying (b), and (c) hand coating techniques to apply edible coatings.

On a laboratory scale, immersion is one of the main methods used for coating fruits due to its simplicity, without dependence on equipment, and uniformity of film obtained. In this method, the entire surface of the food is submerged in the film-forming solution at a constant speed, allowing full surface coverage, ensuring complete surface wetting [47]. After application, the excess solution is drained to eliminate the overload of film-forming solution on the fruit surface [48]. Finally, the food is dried with the excess solvent and liquid being evaporated to leave the film in contact with the food surface. Drying can take place at room temperature or using a heated air tunnel after draining the solution. This technique allows the application of coating solutions with a wide viscosity range [46]. A negative 
point of this technique is the possibility of cross-contamination from fruit to fruit during the immersion process due to the accumulation of residues and microbial organisms [45].

To avoid this problem, products that will be coated must be properly cleaned and sanitized, and the coating solution replaced frequently [15]. According to Raghav et al. [16], in general, fruits and vegetables are immersed for 5-30 s in the coating solution.

In turn, the spraying technique, most popular in packing houses, provides a homogeneous and attractive coating. In addition, it avoids the possibility of contaminating the coating solution [49]. This process increases the liquid surface through the formation of drops and distributes them over the food surface [45]. During spray application, the fruit or vegetable is placed on a plate or rotating rollers at a coordinated speed, under dispersing nozzles activated manually or automatically. This procedure is repeated until the desirable coating thickness is achieved. A drawback of this technique is that viscous solutions cannot be sprayed as they clog the equipment [50].

Another method to apply a filmogenic solution is by gloved hands to the fruit surface. Fruits can be coated by spreading a uniform amount of coating solution by hand while wearing latex gloves. It is appropriate on a laboratory scale to avoid solution contaminations and to minimize waste of experimental coating solutions during screenings. However, a negative aspect consists of the non-homogeneous film thickness formed on the entire fruit surface $[18,35]$.

\section{Nanomaterials in Edible Coatings}

In recent years, nanotechnology has been used as an important tool to increase the storage period for food products. The application of nanoscale particles provides different and improved properties compared to particles with larger size. Related to foods, nanotechnology has a wide spectrum of uses in films and coatings due to the improved features they impart [51].

Figure 4 shows the advances in the development of nanosystems incorporated with food-grade ingredients, which makes it feasible to explore functional modifications in food coating materials that include nanoemulsions, polymeric nanoparticles, nanostructured lipid transporters, nanotubes, nanocrystals, nanofibers, and others [52]. Nanosystems, when incorporated into matrices based on hydrocolloids (proteins or carbohydrates), give rise to nanocomposites, which are the combination of two or more materials, one of which is on a nanoscale, in order to improve coating properties [52,53].

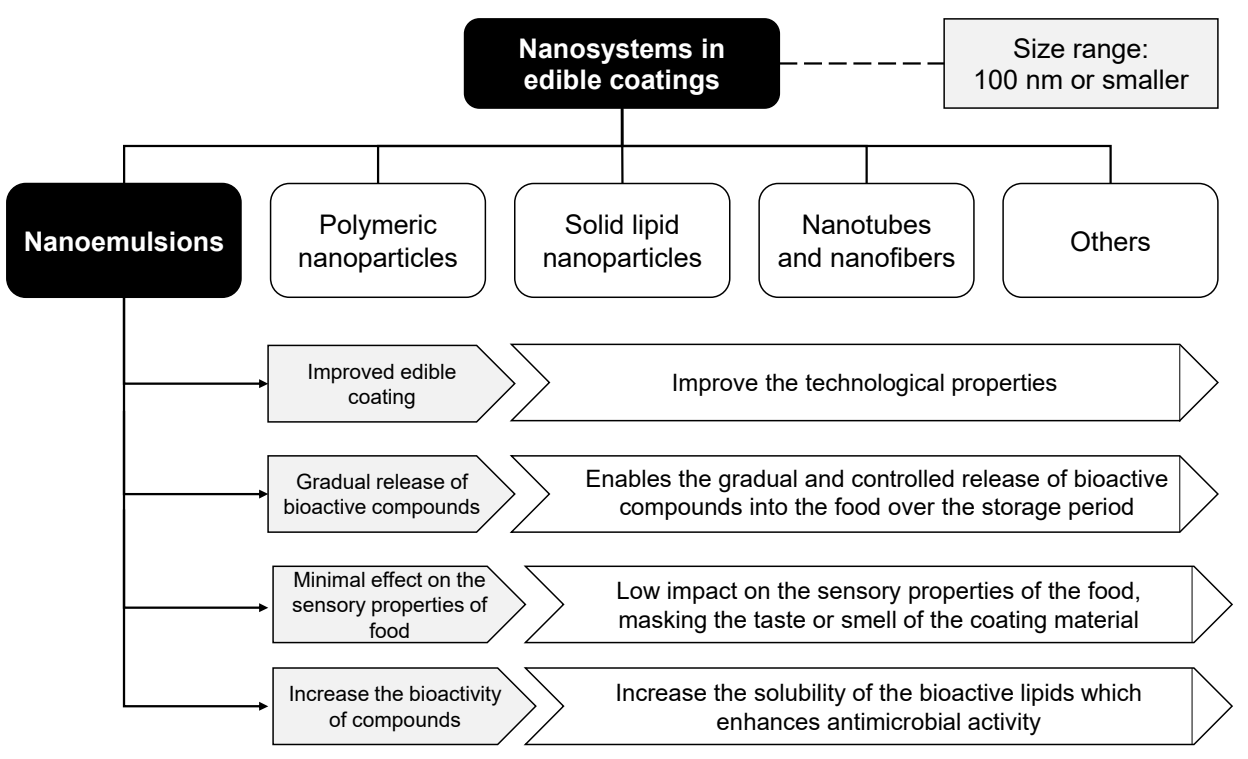

Figure 4. Nanomaterials in edible coatings. 
The main changes due to use of nanosystems in nanocomposite coatings refer to the water barrier, optical and microstructural mechanical properties, and the antimicrobial and antioxidant effects. Nanoparticles in coatings potentiate these activities when antimicrobial or antioxidant compounds are incorporated in the coating, by enabling their gradual and controlled release over the period of fruit storage, sometimes under different storage conditions, hence improving bioavailability of these compounds over time [52,54]. The improvements in these properties are important to guarantee food quality maintenance as well as to reduce the development of decay microorganisms (bacteria, filamentous fungi, and yeasts) and action of free radicals that deteriorate food and reduce shelf life [55]. Another advantage of adding active agents to nanosystems is that a smaller proportion of these substances is necessary to obtain good activity; therefore, the use of these compounds in low concentrations does not negatively affect food sensory properties [12].

\section{Fundamentals of Nanoemulsions}

Emulsions are generally made of two immiscible liquids, commonly oil and water, forming a relatively stable mixture. Generally, emulsions are systems that contain a dispersed and continuous phase and can be classified according to the three-dimensional organization of the oil and water phases. Oil-droplets dispersed within an aqueous phase is named oil-in-water $(O / W)$ emulsion, whereas water-droplets dispersed in the oil phase is classified as water-in-oil (W/O) emulsion, and they are the most common emulsions $[14,56,57]$. Figure 5 shows the schematically structures of $O / W$ (Figure $5 \mathrm{~A}$ ) and W/O (Figure 5B) emulsions, emphasizing the micelle structures dispersed in the continuous phase.

A)

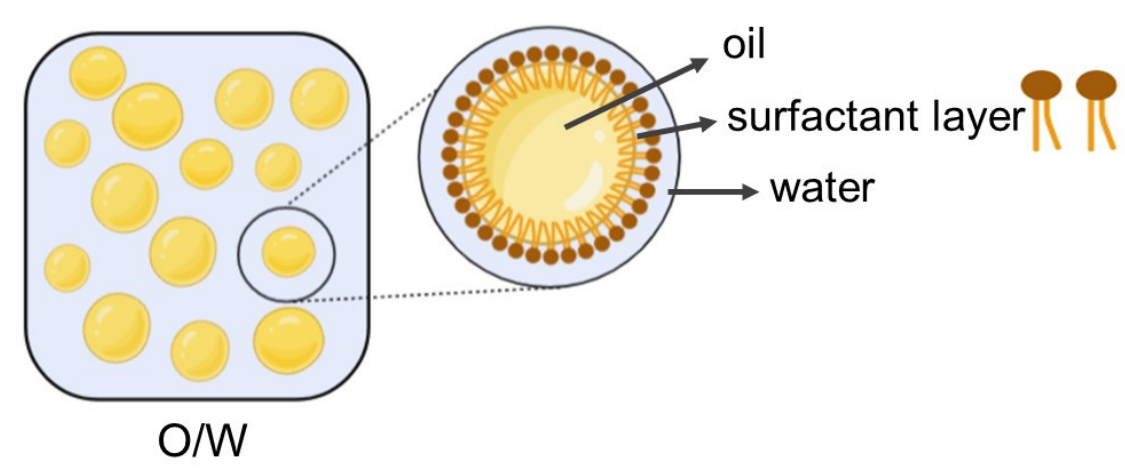

B)

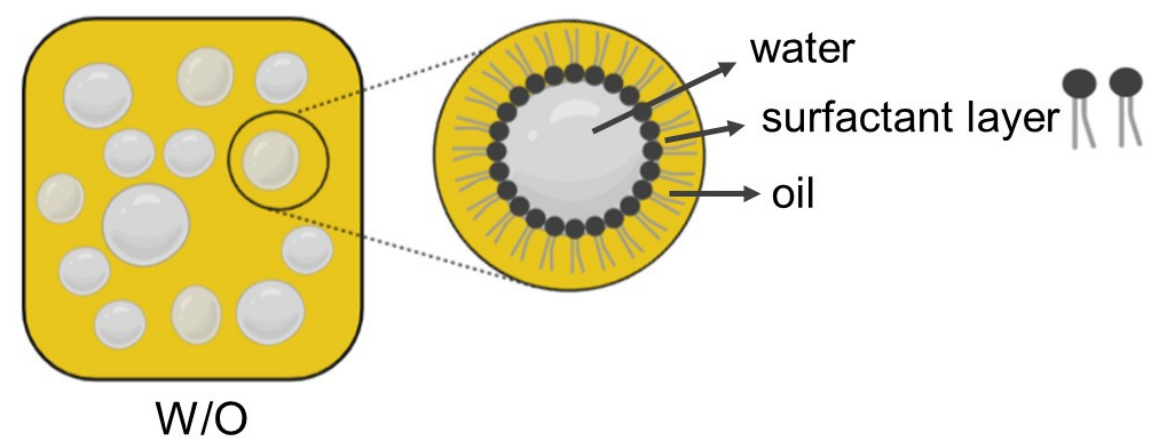

Figure 5. Schematic representation of (A) oil-in-water $(O / W)$ and (B) water-in-oil (W/O) emulsions, representing micelle structure dispersed in continuous phase for each system.

Emulsions are classified into three main classes according to thermodynamic stability, stable mechanisms, and physical properties: macroemulsion or conventional emulsion, nanoemulsion, and microemulsion. Conventional and nanoemulsions are thermodynamically unstable, while the microemulsion is stable. The droplet mean radius for conventional emulsions are bigger, which distinguishes them from nanoemulsions with a radius of less than $100 \mathrm{~nm}[11,57,58]$. The droplet size in nanoemulsions is a key-point that influences 
their capability to improve the bioavailability of added hydrophobic substances, such as carotenoids [58], and increase antimicrobial essential oil properties [59] or oil compounds [60]. The nanoemulsion classes will be further discussed in this article, with the focus of nanoemulsions as edible nanocoatings.

\subsection{Nanoemulsions and Production Methods}

The small size of particles in nanoemulsions allows potential advantages over conventional emulsions, such as greater stability concerning particle aggregation and gravitational separation, in addition to high optical transparency, modification of the physical properties of the coating, and increased bioavailability of bioactive-loaded lipid droplets [57]. Free nanoemulsion-based delivery systems increased the bioaccessibility of vitamins (D) and carotenoids ( $\beta$-carotene and curcumin) $[58,61]$; however, studies have demonstrated that bioactive-loaded nanoemulsions prepared with a biopolymer mixture can be trapped in the matrices and decrease bioaccessibility.

Nanoemulsions need energy for their formation, which is provided by mechanical equipment or physical and chemical properties of the system. Procedures using mechanical energy are called high energy methods and use microfluidizers, high-pressure homogenizers, and ultrasonic homogenizers. The methods that employ the system's physical and chemical properties are categorized as low energy, such as spontaneous emulsification, phase inversion temperature, and emulsion inversion methods [54,57].

When high-energy methods are employed, the surfactants help break oil-droplets inside the homogenizer by decreasing interfacial tension, thus promoting smaller droplets and preventing droplet aggregation. A high shear rate is necessary to break the droplet to form nano-droplets, and is generally achieved by high-pressure homogenizers, as the use of high energy generates forces that can break the droplets in the dispersed phase $[56,57]$. Those methods are well established in the food industry and can be adapted for nanoemulsion production. On the other hand, for low energy methods, surfactants promote small droplet spontaneous formation due to their ability to generate extremely low interfacial tensions under specific conditions. Therefore, the surfactants utilized are extremely important because the emulsion $\mathrm{pH}$ stability, ionic strength, heating, cooling, and storage are mainly determined by the amphiphilic molecule chosen [56,57].

The amphiphilic material, such as surfactants, phospholipids, proteins, and polysaccharides, reduces the interfacial tension and maintains droplet stability. Emulsions $(O / W$ or $W / O$ ) (Figure 6A,B) are the most stable systems; however in unusual regimes, multiple emulsions such as $W / O / W$ and $O / W / O$ (Figure $6 \mathrm{C}, \mathrm{D}$ ) may be formed and are usually extremely unstable to coalescence $[14,54,56]$. Most fruits and vegetables contain a high-water volume; therefore, among emulsions the $O / W$ type (Figure $6 \mathrm{~A}$ ) is the most explored for food systems due to the possibility of loading the oil-droplets with lipophilic key-compounds surrounded by water $[14,54]$.

A) $\mathrm{O} / \mathrm{W}$

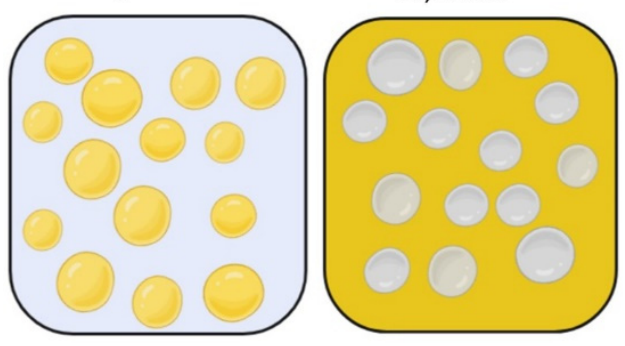

C) $\mathrm{W} / \mathrm{O} / \mathrm{W}$

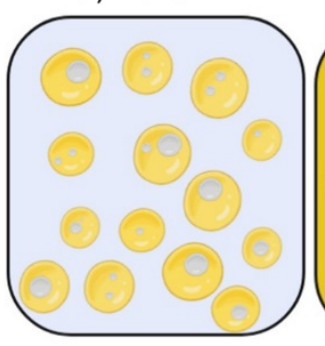

D) $\mathrm{O} / \mathrm{W} / \mathrm{O}$

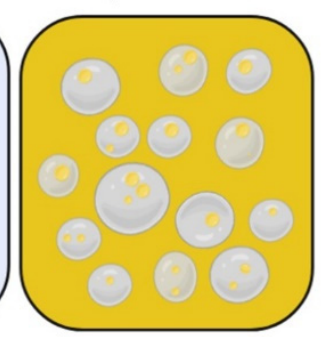

Figure 6. Representation of most common emulsion (A) oil-in-water $(\mathrm{O} / \mathrm{W})$ and $(\mathbf{B})$ water-in-oil $(\mathrm{W} / \mathrm{O})$, and multiple emulsions (C) water-in-oil-in-water (W/O/W) and (D) oil-in-water-in-oil (O/W/O). 


\subsection{Surfactants}

Surfactants can be classified according to their electrical characteristics as ionic, nonionic, and zwitterionic. Most foods surfactants are ionic, such as esterified monoglycerides, which are mainly negatively charged and can form nanoemulsions using low or high energy. Non-ionic surfactants also can be used for both methods and have low toxicity and irritability, including compounds such as Tween ${ }^{\circledR}$ (condensate of sorbitol fatty acid esters and ethylene oxide) and Span ${ }^{\circledR}$ (a family of fatty acids sorbitan). On the other hand, zwitterionic surfactants contain two or more ionizable groups with opposite charges, and consequently, they can have a negative, positive, or neutral charge depending on the $\mathrm{pH}$ solution. For example, this group includes lecithin, a phospholipid widely used in foods $[57,62]$.

One of the main aspects of an emulsion formulation is the choice of surfactant. The hydrophilic-lipophilic Balance (HLB) system was developed, which represents the balance of the size and strength of the polar and non-polar groups [62]. It demonstrates molecule properties as amphiphilic compounds using a numerical scale, assigning higher HLB values as the substance is more hydrophilic [62]. However, the HLB system only considers the properties of the surfactant itself. For this reason, the hydrophilic-lipophilic deviation (HLD) system is another approach to the behavior exhibited by surfactantoil-water and usually more suitable in formulations $[57,63]$. In addition, proteins, polymers with amphiphilic properties, and combinations of polymers and surfactants can act as emulsifiers [64].

Studies have demonstrated the importance of modulating nanoemulsions composition and structure to achieve higher digestion and absorption in the gastrointestinal tract and to efficiently deliver compounds such as vitamins and nutraceuticals $[54,58,65,66]$. Therefore, the choice of emulsifier is of extreme importance since it can improve carotenoids bio-accessibility, for example. In a study performed by Yao et al. (2019) [65], the authors demonstrated the relationship between carotenoids bio-accessibility from spinach and co-ingesting with excipient nanoemulsions: nanoemulsions containing different ratios of medium or long-chain triglycerides in the oil phase composition decreased $\beta$-carotene bioaccessibility when the ratio of medium-chain triglycerides was increased. The findings were credited to the formed micelle's ability to hold the carotenoids in their hydrophobic domains.

\section{Plant-Based Nanoemulsions as Edible Coatings on Fruits and Vegetables Postharvest 6.1. Coatings Based on Essential Oil Nanoemulsions}

One of the main features can be in the form of antimicrobial nanoemulsions, for example, nanoemulsions based on plant essential oils, which are associated with biopolymers such as alginate, chitosan, and starch, among others. It has been shown that when essential oils are encapsulated in nanoemulsions, they have less impact on the sensory properties of the food, masking the taste or smell of the core material (coating), yet providing better biological activity of essential oils due to the increase in the surface area [67]. In this way, it is possible to use low doses of bioactive material, increasing the transport of active ingredients through biological membranes, thus intensifying the bioavailability of bioactive compounds, in addition to less interaction with other components of the food matrix. Other advantages are the low mass transport of compounds into and out of the coating, less impact on optical, barrier, and microstructural properties and greater coating stability $[68,69]$.

Essential oils have received special attention as active ingredients applicable in food coatings, due to their potent antimicrobial and antioxidant activities [70]. Essential oils are volatile aromatic substances of low molecular weight (for example, phenolic compounds, such as monoterpenes, flavonoids, and phenolic acids) produced by plants (for example, cinnamon, thyme, lavender, ginger, palmarosa, lemongrass, mint, citrus fruits, and fennel) or their isolated components (for example, eugenol, geraniol, menthol, limonene, carvacrol, and linalool) that can reduce microbial growth in food, and have been studied as natural antimicrobials in food for decades [71]. However, their volatile nature, low 
water solubility, and strong aroma limit their applications in foods. In this sense, using nanotechnological approaches is a promising strategy to enable the application of essential oils as natural antimicrobials in foods, overcoming their limitations and increasing their antimicrobial activity [52].

Table 2 presents the main types of nanoemulsions as edible coatings classified by matrix type and their impact on fruit and vegetable shelf life.

Table 2. Main types nanoemulsions as edible coatings and their impact on fruit and vegetable shelf life.

\begin{tabular}{|c|c|c|c|c|c|}
\hline Matrix & $\begin{array}{l}\text { Bioactive Substance or } \\
\text { Lipid Compound }\end{array}$ & $\begin{array}{l}\text { Production } \\
\text { Technique }\end{array}$ & Functionality & Fruit or Vegetable & Reference \\
\hline Modified chitosan & $\begin{array}{l}\text { Lemon, mandarin, } \\
\text { oregano, or clove } \\
\text { essential oils }\end{array}$ & $\begin{array}{c}\text { High-pressure } \\
\text { homogenization }(\mathrm{HPH})\end{array}$ & $\begin{array}{l}\text { Increase the antimicrobial } \\
\text { activity of the essential oil } \\
\text { and improve the homogeneity } \\
\text { and stability of the emulsion }\end{array}$ & $\begin{array}{l}\text { Arugula leaf } \\
(\text { Eruca sativa) }\end{array}$ & [72] \\
\hline Chitosan & $\begin{array}{l}\text { Carvacrol, bergamot, } \\
\text { mandarin, and lemon } \\
\text { essential oils }\end{array}$ & $\begin{array}{l}\text { High-pressure } \\
\text { homogenization }\end{array}$ & $\begin{array}{l}\text { Increase the antimicrobial } \\
\text { activity of essential oils }\end{array}$ & $\begin{array}{c}\text { Green beans } \\
\text { (Phaseolus vulgaris) }\end{array}$ & [73] \\
\hline Sodium alginate & Basil essential oil & Ultrasound & $\begin{array}{l}\text { Increase the antimicrobial } \\
\text { activity of essential oil }\end{array}$ & $\begin{array}{c}\text { Okra (Abelmoschus } \\
\text { esculentus) }\end{array}$ & {$[74]$} \\
\hline Pullulan & Cinnamon essential oil & Ultrasound & $\begin{array}{l}\text { Improve the distribution of } \\
\text { oil in the matrix and increase } \\
\text { its antimicrobial activity }\end{array}$ & $\begin{array}{c}\text { Strawberry } \\
(\text { Fragaria } \times \text { ananassa })\end{array}$ & [75] \\
\hline Carnauba wax & Lemongrass essential oil & Dynamic high pressure & $\begin{array}{l}\text { Increase the antimicrobial } \\
\text { activity of the essential oil } \\
\text { and improve the homogeneity } \\
\text { and stability of the emulsion }\end{array}$ & $\begin{array}{c}\text { Plums } \\
\text { (Prunus salicina) }\end{array}$ & {$[76]$} \\
\hline Carnauba wax & Lemongrass essential oil & $\begin{array}{l}\text { High shear probe and } \\
\text { high-pressure dynamic } \\
\text { processing (DHP) }\end{array}$ & $\begin{array}{l}\text { Increase the antimicrobial } \\
\text { activity of essential oil }\end{array}$ & $\begin{array}{l}\text { Grape berry (Vitis } \\
\text { labruscana Bailey) }\end{array}$ & [77] \\
\hline Candelilla wax & Extract of tarbush & High-speed stirrer & $\begin{array}{l}\text { Improved the wettability of } \\
\text { the nanocoating on the Fuji } \\
\text { apple surface }\end{array}$ & $\begin{array}{l}\text { Fuji apple (Malus } \\
\text { domestica 'Fuji) }\end{array}$ & [78] \\
\hline $\begin{array}{l}\text { Quinoa } \\
\text { protein/chitosan }\end{array}$ & Thymol & $1200 \mathrm{rpm}$ agitation & $\begin{array}{l}\text { Increase the antimicrobial } \\
\text { activity of the active } \\
\text { compound and improve } \\
\text { dispersion in the matrix }\end{array}$ & $\begin{array}{c}\text { Strawberry } \\
(\text { Fragaria } \times \text { ananassa })\end{array}$ & [79] \\
\hline Sodium alginate & Lemongrass essential oil & Microfluidization & $\begin{array}{l}\text { Improve the stability of the } \\
\text { emulsion and increase the } \\
\text { antimicrobial activity of the } \\
\text { essential oil }\end{array}$ & $\begin{array}{l}\text { Fresh-cut Fuji apples } \\
\text { (Malus domestica 'Fuji) }\end{array}$ & {$[59]$} \\
\hline $\begin{array}{l}\text { Hydroxypropyl } \\
\text { methylcellulose }\end{array}$ & $\begin{array}{l}\text { Carnauba wax } \\
\text { nano-emulsion }\end{array}$ & $\begin{array}{c}\text { High-pressure } \\
\text { homogenization }(\mathrm{HPH}) \\
\text { and mechanical stirring }\end{array}$ & $\begin{array}{l}\text { Reduce gas permeability and } \\
\text { moisture loss }\end{array}$ & $\begin{array}{l}\text { 'Redtainung' } \\
\text { Papaya } \\
\text { (Carica papaya) }\end{array}$ & {$[28]$} \\
\hline Sodium alginate & Citral & Ultrasound & $\begin{array}{l}\text { Improve the dispersion of the } \\
\text { active compound in the } \\
\text { matrix and increase its } \\
\text { antimicrobial activity }\end{array}$ & $\begin{array}{l}\text { Fresh cut pineapples } \\
\text { (Ananas comosus) }\end{array}$ & {$[60]$} \\
\hline Carnauba wax & $\begin{array}{l}\text { Oleic acid and } \\
\text { Carnauba wax }\end{array}$ & $\begin{array}{c}\text { High-pressure } \\
\text { homogenization }(\mathrm{HPH})\end{array}$ & $\begin{array}{l}\text { Improve optical properties, } \\
\text { and emulsion stability }\end{array}$ & $\begin{array}{l}\text { 'Nova' mandarins } \\
\text { (Citrus reticulata) and } \\
\text { 'Unique' tangors } \\
\text { (C. reticulata } \text { C. sinensis) }\end{array}$ & [18] \\
\hline Chitosan & $\begin{array}{l}\text { Cellulose nanocrystal and } \\
\text { oleic acid }\end{array}$ & $\begin{array}{l}\text { Ultra turrax } \\
\text { homogenizer }\end{array}$ & $\begin{array}{l}\text { Increase coating stability at } \\
\text { high humidity, adhesion on } \\
\text { fruit surface and delayed } \\
\text { ripening of pears }\end{array}$ & $\begin{array}{c}\text { Bartlett pears } \\
\text { (Pyrus communis) }\end{array}$ & [80] \\
\hline
\end{tabular}

Edible coatings based on nanoemulsions of essential oils have been studied as an alternative to prolong fresh fruit and vegetable shelf life. For example, a coating based on the nanoemulsion of lemon essential oil and chitosan increased the shelf life of arugula leaves by 7 days compared to a coating of chitosan or lemon oil alone [72]. Likewise, coatings based on modified chitosan and carvacrol nanoemulsions completely inhibited the growth of Escherichia coli on fresh green beans during the 11-day period under refrigeration [73]. Gundewadi et al. [74] also reported that the nanoemulsification of basil essential oil in an alginate coating was more effective than its respective microemulsion and presented better coating stability. In addition, when applied to okra fruits, nanoemulsion was more 
efficient in preserving texture, color, and sensory characteristics compared to control fruits. The essential oil of nanoemulsified basil showed greater antifungal activity against fungal pathogens than microemulsions. Chu et al. [75] developed a pullulan coating with a cinnamon essential oil nanoemulsion for strawberry storage. The nanoemulsion-based coating was more effective than other coatings in reducing loss of mass, firmness, total soluble solids, acidity, and controlling the growth of fungi and bacteria during fruit storage.

In another study, Prakash, Baskaran, and Vadivel [60], evaluated the effect of a coating based on sodium alginate and citral nanoemulsion on the quality of fresh cut pineapples. Coatings based on nanoemulsions were effective at reducing microbial growth during storage. In addition, at a concentration of $0.2 \%$ of citral nanoemulsion, the coating reduced the presence of Salmonella enterica and Listeria monocytogenes after artificial inoculation [60]. The coating based on nanoemulsions of lemongrass essential oil, Tween ${ }^{\circledR} 80$ and alginate was more effective at preserving the characteristics of minimally processed Fuji apples than their respective conventional emulsions. The nanoemulsion coating inhibited the growth of artificially inoculated E. coli on fruits faster than conventional emulsions [59].

\subsection{Coatings Based on Plant-Based Wax Nanoemulsions}

Commercial coatings based on approved waxes must meet state/national fruit and vegetable additive regulations and be considered safe for consumption. However, to improve the characteristics of wax-based coatings, they are combined with synthetic chemicals to prevent microbiological deterioration and to ensure homogeneous stability of the coating during product storage. Commercial coatings are typically formulated using oxidized polyethylene wax (a by-product of the petroleum industry), carnauba wax (from the leaves of the carnauba palm, Copernicia cerifera), candelilla wax (from the candelilla shrub, Euphorbia cerifera), and shellac (from the insect bug Kerria lacca) as matrices, combined with water and other agents such as oleic acid, morpholine, ammonia, polydimethylsiloxane antifoam, and others [81].

The compounds combined with waxes used as emulsifying, moisturizing, and antimicrobial agents in commercial coatings, are mostly synthetic chemical products and could be a concern for human health [82]. As an example, morpholine is a base acting as a counterion to facilitate fatty acids emulsification in waxes. In the presence of nitrite/nitrate, morpholine can form N-nitrosomorpholine, a potent mutagen and carcinogen [83,84]. Nnitrosomorpholine was not found on coated fruit surface, but the possibility of its formation in the gut from reaction of morpholine with dietary nitrates was considered; it was found at concentrations less than the safe dose of $4.3 \mathrm{ng} / \mathrm{kg}$ body weight/day, not enough to raise concerns [85]. Ammonia could be used as a replacement for morpholine [86], but its highly volatile and irritant nature makes it less easy to use than morpholine.

Consumers are increasingly concerned about the safety and quality of food, driving the demand for so-called "environmentally friendly coatings", that is, coatings based on natural products of plant origin that do not present any harm to the consumer's health if consumed. The use of waxes and compounds of animal origin has been limited by vegan and vegetarian consumers, consumers who are allergic to animal products (such as chitosan) and religious beliefs that do not encourage the consumption of animals [87]. Therefore, the demand for plant-based wax-based coatings is an important market for fresh fruits and vegetables, and nanotechnology is a promising tool to meet this demand by improving the properties of these coatings, especially wax-based ones, reducing the need of synthetic additives.

Nanotechnology has been successfully used to produce plant-based waxes nanoemulsions, such as carnauba wax [18] and candelilla wax [78] without the addition of morpholine. Wax-based nanoemulsions can have improved barrier properties due to the small size of the droplets, promoting greater homogeneity compared to conventional emulsions, greater transparency, improved physico-chemical properties (optical, mechanical, and barrier) and greater stability in comparison with conventional emulsions $[18,54,78]$. In addition, these nanoemulsions can be used for the development of nanocomposite coatings, in combina- 
tion with hydrocolloid components (polysaccharides and proteins) in order to improve the water barrier properties of these compounds and minimize the impact of the incorporation of lipid compounds in the matrix hydrocolloids [29].

Lipid nanoemulsions made from plant-based waxes have shown greater effectiveness as edible coatings than conventional emulsions on fresh fruits and vegetables preservation (Table 2). The carnauba wax nanoemulsion coating showed less water loss, conferred gloss, and caused less ethanol production than shellac in coated 'Nova' mandarins (Citrus reticulata) and 'Unique' tangors (C. sinensis) [18]. In addition, the coating based on carnauba wax nanoemulsion exhibited less changes in the fruit internal atmosphere and volatile profile, and consequently, better flavor compared to the conventional carnauba wax emulsion and commercial shellac [18].

Lipid nanoemulsions produced from waxes, such as carnauba or candelilla, have been shown to be suitable vehicles for carrying bioactive compounds, such as plant extracts and essential oils $[78,88]$. They can improve the physical stability of the active substances, and improve the bioactivity of these compounds, and due to the prolonged and slow diffusion, they reduce the impact of these substances on the sensory properties of fruits and vegetables [88]. De Léon-Zapata et al. [78] developed candelilla wax nanoemulsions added with tarbush extract and evaluated its effect on the preservation of Fuji apples. The combination of extract and nanocoating reduced the size of the droplets and improved the zeta potential and optical properties of the coating. When applied to Fuji apples, the nanocoating effectively reduced physico-chemical and microbiological changes and delayed fruit senescence in comparison with the control treatment.

In another study, a nanoemulsion of carnauba wax combined with lemongrass essential oil nanoemulsion was applied to plums [76]. The coatings were able to inhibit the growth of S. typhimurium (S. enterica) and E. coli O157: H7 inoculated plums during storage, and did not significantly affect their taste and appearance (brightness). In addition, nanoemulsion coatings were effective at reducing weight loss, ethylene production and respiration rate. Fruit coated with nanoemulsions showed greater firmness and increase in phenolic compounds content during storage in comparison with uncoated fruits [76]. A similar result was observed in another study carried out by these authors with grape berries. The coating based on carnauba wax and lemongrass essential oil nanoemulsion inhibited the growth of S. typhimurium and E. coli O157: H7 inoculated fruit. Lemongrass in nanoemulsions did not affect berry taste and improved their brightness. Coatings based on nanoemulsions were also able to reduce weight loss and maintain firmness, phenolic compounds, and antioxidant activity in berries. The coatings demonstrated the potential to reduce microbiological contamination of grape berries by foodborne pathogens and prolong their shelf life. [77].

\section{Trends in Materials Based on Nanoemulsions with Potential for Application in the Preservation of Fruits and Vegetables}

New coating materials based on nanoemulsions with potential for application in fruits and vegetables have been developed in the last two years with the aim of contributing even more to the preservation of these products. One way to develop these functionalized materials is to combine composites with different properties to develop a functionalized coating. For example, de Oliveira Filho et al. [89] developed a functionalized coating combining arrowroot starch (biopolymeric matrix), carnauba wax nanoemulsion (to improve the water barrier properties of the coating), cellulose nanocrystals (to improve mechanical properties and stabilize the emulsion), and essential oils (to confer antimicrobial activity). The combination of compounds resulted in a coating material with excellent water barrier, mechanical, thermal, optical, microstructural, and antimicrobial properties against fungi that attack fruits during post-harvest.

Another increasingly explored trend in the development of new coatings based on nanoemulsions with better stabilities is the use of solid particles to form Pikering nanoemulsions, that is, nanoemulsions stabilized with solid particles such as cellulose 
nanocrystals [90], starch nanocrystals [91], $\gamma$-Al2O3 nanoparticles [92], cyclodextrin [93], among others.

Pickering nanoemulsions have excellent stability due to irreversible adsorption that occurs between solid particles at the oil-water interface due to the high adsorption energy [94]. Another characteristic of these nanoemulsions is the ability to release active ingredients encapsulated under specific conditions, such as $\mathrm{pH}$ and temperature [93]. Almasi, Azizi, and Amjadi [95] compared two coating materials based on pectin, one with marjoram essential oil encapsulated in a whey protein/inulin stabilized Pickering nanoemulsion, and the other with marjoram essential oil nanoemulsified with Tween 80 . Coatings based on pectin with Pickering nanoemulsions presented mechanical and water barrier properties superior to those based on standard nanoemulsion. In another study, López-Monterrubio et al. [96] developed highly efficient $\beta$-carotene nanoemulsions stabilized by a complex formed by hydrolyzed whey protein and pectin. The nanoemulsions showed good stability during the 30-day storage period with low formation of clumps.

Deng et al. [80] developed coatings based on chitosan and Pickering nanoemulsion of oleic acid stabilized with cellulose nanocrystals and evaluated their effects on the postharvest conservation of green D'Anjou and Bartlett pears (Pyrus communis L.). The coating formulated with $5 \%$ cellulose nanocrystals showed strong adhesion to the fruit surface, showing greater gas barrier property compared to the commercial Semperfresh ${ }^{\mathrm{TM}}$ product, and presented a more homogeneous matrix, being effective in delaying ripening and increased the shelf life of pears during storage.

Although the above new materials have been little studied in food systems, the results described in the literature are very encouraging.

\section{Potential Toxicity, Limitations, and Regulatory Aspects of Nanoemulsions}

Nanoemulsions, due to the nanometric size of the droplets, may partially remain intact during digestion, representing potential safety risks related to the compounds used for their production (such as surfactants). They can be of concern in metabolic or hormonal dysregulation due to their rapid absorption compared to conventional emulsions, their ability to increase the bioavailability of bioactive agents to a toxic level, and the possibility of increased absorption by epithelial cells which can cause changes in the functionality of the gastrointestinal tract [97]. However, as they have a high surface area, nanoemulsions can also be quickly digested by enzymes from the gastrointestinal tract, reducing the possible toxic effect that can occur due to their accumulation in organ cells [98].

In vitro studies were performed using cell cultures, usually models of normal cells such as fibroblasts, to investigate potential toxicity of nanoemulsions. Kaur et al. [99] reported that nanoemulsions based on tocopheryl polyethylene glycol succinate (TPGS), lemon oil, Tween-80, and water did not show toxicity in Hep G2 cells. In another study, Marchese et al. [100] observed that bergamot essential oil nanoemulsions showed cytotoxic activity against Caco 2 cells at high concentrations. A limitation of these studies is the fact that authors have not previously exposed the nanoemulsions in simulated conditions of the gastrointestinal tract before contact with the cells.

Knowledge about the potential toxicity of nanoemulsions in vivo is still limited and should be investigated [97]. The effect of nanoemulsions based on antimicrobial compounds, such as essential oils, on the gastrointestinal tract is also poorly reported in the literature. This effect must be carefully studied, as antimicrobial compounds can influence the intestinal microbiota or epithelial cells of the gastrointestinal tract.

In a recent study, Hort et al. [101] evaluated the toxicity of Miglyol and egg lecithin nanoemulsions using an in vivo model (male Wistar rats). The nanoemulsions were orally administered to rats for 21 days at lipid concentrations of 200,400 , or $800 \mathrm{mg} / \mathrm{kg}$ of body weight. The results of biochemical, hematological, oxidative stress, and genotoxicity parameters showed that nanoemulsions could be considered safe for oral administration, but high doses by the parenteral route could cause toxic effects. 
The few studies suggest that nanoemulsions formulated with GRAS ingredients do not exhibit strong cytotoxic effects. The nanometer size of the droplets suggests that they are rapidly transformed into monoglycerides and free fatty acids in the small intestine, which are normal digestion products and should not have toxic effects [57].

As for regulatory aspects, essential oils and other antimicrobial agents are mainly regulated by the European Food Safety Authority (EFSA) in Europe and the Food and Drug Administration (FDA) in the United States [102]. However, for nanoemulsions there is no international authority that makes this regulation. The FDA addresses the regulation of nanotechnology products as guidance for industries. The European Council and Parliament have regulated food nanotechnology as new food products or food ingredients [103].

\section{Conclusions and Future Perspectives}

The use of substances obtained from plant-based natural sources has emerged as a trend in the fresh fruit and vegetable market for coating applications. The application of these compounds on a nanoscale has advantages allowing a wider use in relation to particles on larger scales. Recent studies indicate that nanoemulsions play an important role in the development of a new generation of coatings with improved properties for the preservation of fresh fruits and vegetables. This emerging technology makes it possible to improve the physical stability and performance of active substances within an edible coating, bringing the possibility of increasing the quality and/or nutritional value of fruits and vegetables. Although the evidence published to date suggests that nanoemulsions applied as edible coatings can extend the life of different fruits and vegetables, there are other important aspects to explore before considering them on a commercial scale in future trends, such as the bioavailability of bioactive compounds incorporated in the nanoemulsions, potential toxicity and digestibility, for example. Most of the tested nanoemulsion coatings have antimicrobial properties; however, it can also be possible to produce and apply edible coatings with health-promoting substances.

Author Contributions: Writing—original draft preparation, J.G.d.O.F. and M.M.; writing—review and editing, M.D.F. and A.P.; visualization, J.G.d.O.F. and M.M.; supervision, M.D.F.; project administration, M.D.F.; funding acquisition, M.D.F. All authors have read and agreed to the published version of the manuscript.

Funding: This research was funded by FAPESP (process 2016/23419-5,2018/10657-0, and 2018/24612-9), CAPES (001), CNPq (process 407956/2016-6; fellowship 310728/2019-3), Empresa Brasileira de Pesquisa Agropecuária (Embrapa), Rede Agronano, and MCTI-SisNano from Brazil.

Acknowledgments: Authors thank Elizabeth Baldwin for reviewing the manuscript and constructive suggestions.

Conflicts of Interest: The authors declare no conflict of interest.

Disclaimer: Mention of a trademark or proprietary product is for identification only and does not imply a guarantee or warranty of the product by the U.S. Department of Agriculture. The U.S. Department of Agriculture prohibits discrimination in all its programs and activities on the basis of race, color, national origin, gender, religion, age, disability, political beliefs, sexual orientation, and marital or family status.

\section{References}

1. Dhandevi, P.; Jeewon, R. Fruit and vegetable intake: Benefits and progress of nutrition education interventions-narrative review article. Iran. J. Public Health 2015, 44, 1309-1321.

2. Brizzolara, S.; Manganaris, G.A.; Fotopoulos, V.; Watkins, C.B.; Tonutti, P. Primary metabolism in fresh fruits during storage. Front. Plant Sci. 2020, 11, 80. [CrossRef] [PubMed]

3. Anwar, R.; Mattoo, A.K.; Handa, A.K. Ripening and senescence of fleshy fruits. In Postharvest Biology and Nanotechnology; Paliyath, G., Subramanian, J., Lim, L.-T., Subramanian, K.S., Handa, A.K., Mattoo, A.K., Eds.; John Wiley \& Sons, Inc.: Hoboken, NJ, USA, 2019; pp. 15-51.

4. Nunes, C.N.; Emond, J.-P. Relationship between weight loss and visual quality of fruits and vegetables. Proc. Fla. State Hort. Soc. 2007, 120, 235-245. 
5. Baldwin, E.A. Edible coatings for fresh fruits and vegetables: Past, present, and future. Edible Coat. Film. Improv. Food Qual. 1994, 1, 25.

6. Acevedo-Fani, A.; Soliva-Fortuny, R.; Martín-Belloso, O. Nanoemulsions as edible coatings. Curr. Opin. Food Sci. 2017, 15, 43-49. [CrossRef]

7. Bai, J.; Baldwin, E.A.; Hagenmaier, R.H. Alternatives to shellac coatings provide comparable gloss, internal gas modification, and quality for 'Delicious' apple fruit. HortScience 2002, 37, 559-563. [CrossRef]

8. Navarro-Tarazaga, M.-L.; Perez-Gago, M.-B.; Goodner, K.; Plotto, A. A new composite coating containing HPMC, beeswax, and Shellac for 'Valencia' oranges and 'Marisol' tangerines. Proc. Fla. State Hort. Soc. 2007, 120, 228-234.

9. Valencia-Chamorro, S.A.; Pérez-Gago, M.B.; del Río, M.Á.; Palou, L. Effect of antifungal hydroxypropyl methylcellulose (HPMC)lipid edible composite coatings on postharvest decay development and quality attributes of cold-stored 'Valencia' oranges. Postharvest Biol. Technol. 2009, 54, 72-79. [CrossRef]

10. Nawab, A.; Alam, F.; Hasnain, A. Mango kernel starch as a novel edible coating for enhancing shelf-life of tomato (Solanum lycopersicum) fruit. Int. J. Biol. Macromol. 2017, 103, 581-586. [CrossRef]

11. McClements, D.J. Nanoemulsions versus microemulsions: Terminology, differences, and similarities. Soft Matter 2012, 8, 1719-1729. [CrossRef]

12. Hasan, S.K.; Ferrentino, G.; Scampicchio, M. Nanoemulsion as advanced edible coatings to preserve the quality of fresh-cut fruits and vegetables: A review. Int. J. Food Sci. Technol. 2020, 55, 1-10. [CrossRef]

13. Salvia-Trujillo, L.; Soliva-Fortuny, R.; Rojas-Graü, M.A.; McClements, D.J.; Martín-Belloso, O. Edible nanoemulsions as carriers of active ingredients: A review. Annu. Rev. Food Sci. Technol. 2017, 8, 439-466. [CrossRef]

14. Jin, W.; Xu, W.; Liang, H.; Li, Y.; Liu, S.; Li, B. Nanoemulsions for food: Properties, production, characterization, and applications. In Emulsions; Grumezescu, A.M., Ed.; Elsevier: Amsterdam, The Netherlands, 2016; pp. 1-36.

15. Andrade, R.D.; Skurtys, O.; Osorio, F.A. Atomizing spray systems for application of edible coatings. Compr. Rev. Food Sci. Food Saf. 2012, 11, 323-337. [CrossRef]

16. Raghav, P.K.; Agarwal, N.; Saini, M. Edible coating of fruits and vegetables: A review. Int. J. Sci. Res. Mod. Educ. 2016, I, 188-204.

17. Ghoora, M.D.; Srividya, N. Effect of packaging and coating technique on postharvest quality and shelf life of Raphanus sativus L. and Hibiscus sabdariffa L. microgreens. Foods 2020, 9, 653. [CrossRef]

18. Miranda, M.; Sun, X.; Ference, C.; Plotto, A.; Bai, J.; Wood, D.; Assis, O.B.G.; Ferreira, M.D.; Baldwin, E. Nano-and Micro-Carnauba Wax Emulsions versus Shellac Protective Coatings on Postharvest Citrus Quality. J. Am. Soc. Hortic. Sci. 2020, 1, 1-10. [CrossRef]

19. Burdock, G.A.; Carabin, I.G. Generally recognized as safe (GRAS): History and description. Toxicol. Lett. 2004, 150, 3-18. [CrossRef]

20. Riva, S.C.; Opara, U.O.; Fawole, O.A. Recent developments on postharvest application of edible coatings on stone fruit: A review. Sci. Hortic. 2020, 262, 109074. [CrossRef]

21. Thakur, R.; Pristijono, P.; Scarlett, C.J.; Bowyer, M.; Singh, S.; Vuong, Q.V. Starch-based films: Major factors affecting their properties. Int. J. Biol. Macromol. 2019, 132, 1079-1089. [CrossRef]

22. Mohamed, S.A.; El-Sakhawy, M.; El-Sakhawy, M.A.-M. Polysaccharides, protein and lipid-based natural edible films in food packaging: A review. Carbohydr. Polym. 2020, 238, 116178. [CrossRef]

23. Dehghani, S.; Hosseini, S.V.; Regenstein, J.M. Edible films and coatings in seafood preservation: A review. Food Chem. 2018, 240, 505-513. [CrossRef]

24. Eddin, A.S.; Ibrahim, S.A.; Tahergorabi, R. Egg quality and safety with an overview of edible coating application for egg preservation. Food Chem. 2019, 296, 29-39. [CrossRef] [PubMed]

25. Arnon-Rips, H.; Poverenov, E. Improving food products' quality and storability by using Layer by Layer edible coatings. Trends Food Sci. Technol. 2018, 75, 81-92. [CrossRef]

26. Galus, S.; Kadzińska, J. Food applications of emulsion-based edible films and coatings. Trends Food Sci. Technol. 2015, 45, 273-283. [CrossRef]

27. Dhumal, C.V.; Sarkar, P. Composite edible films and coatings from food-grade biopolymers. J. Food Sci. Technol. 2018, 55, 4369-4383. [CrossRef] [PubMed]

28. Miranda, M.; Gozalbo, A.M.; Sun, X.; Plotto, A.; Bai, J.; de Assis, O.; Ferreira, M.; Baldwin, E. Effect of mono and bilayer of carnauba wax based nano-emulsion and HPMC coatings on popst-harvest quality of 'redtainung' papaya. In Proceedings of the Embrapa Instrumentação-Artigo em anais de congresso (ALICE), São Carlos, Brazil, 3-5 December 2019.

29. De Oliveira Filho, J.G.; Bezerra, C.C.d.O.N.; Albiero, B.R.; Oldoni, F.C.A.; Miranda, M.; Egea, M.B.; de Azeredo, H.M.C.; Ferreira, M.D. New approach in the development of edible films: The use of carnauba wax micro-or nanoemulsions in arrowroot starch-based films. Food Packag. Shelf Life 2020, 26, 100589. [CrossRef]

30. Bodbodak, S.; Moshfeghifar, M. Advances in modified atmosphere packaging of fruits and vegetables. In Eco-Friendly Technology for Postharvest Produce Quality; Siddiqui, M.W., Ed.; Elsevier: Amsterdam, The Netherlands, 2016; pp. 127-183.

31. Nor, S.M.; Ding, P. Trends and advances in edible biopolymer coating for tropical fruit: A review. Food Res. Int. 2020, 134, 109208. [CrossRef]

32. Porat, R.; Fallik, E. Production of off-flavours in fruit and vegetables under fermentative conditions. In Fruit and Vegetable Flavour; Brückner, B., Wyllie, S.G., Eds.; Elsevier: Amsterdam, The Netherlands, 2008; pp. 150-164.

33. Baldwin, E.A.; Nisperos-Carriedo, M.; Shaw, P.E.; Burns, J.K. Effect of coatings and prolonged storage conditions on fresh orange flavor volatiles, degrees brix, and ascorbic acid levels. J. Agric. Food Chem. 1995, 43, 1321-1331. [CrossRef]

34. Quirós-Sauceda, A.E.; Ayala-Zavala, J.F.; Olivas, G.I.; González-Aguilar, G.A. Edible coatings as encapsulating matrices for bioactive compounds: A review. J. Food Sci. Technol. 2014, 51, 1674-1685. [CrossRef] [PubMed]

35. Sun, X.; Baldwin, E.; Ritenour, M.; Plotto, A.; Bai, J. Evaluation of natural colorants and their application on citrus fruit as alternatives to Citrus Red No. 2. HortScience 2015, 50, 1353-1357. [CrossRef] 
36. Marin, A.; Sun, X.; Miranda, M.; Ference, C.; Baldwin, E.A.; Bai, J.; Ritenour, M.A.; Zhang, J.; Plotto, A. Optimizing Essential Oil Applications to Prevent Postharvest Decay in Strawberries. Proc. Fla. State Hort. Soc 2019, 132, 185-188.

37. Basaglia, R.R.; Pizato, S.; Santiago, N.G.; de Almeida, M.M.M.; Pinedo, R.A.; Cortez-Vega, W.R. Effect of edible chitosan and cinnamon essential oil coatings on the shelf life of minimally processed pineapple (Smooth cayenne). Food Biosci. 2021, 41, 100966. [CrossRef]

38. De Oliveira Filho, J.G.; da Cruz Silva, G.; de Aguiar, A.C.; Cipriano, L.; de Azeredo, H.M.C.; Junior, S.B.; Ferreira, M.D. Chemical composition and antifungal activity of essential oils and their combinations against Botrytis cinerea in strawberries. J. Food Meas. Charact. 2021, 15, 1815-1825. [CrossRef]

39. Tesfay, S.Z.; Magwaza, L.S.; Mbili, N.; Mditshwa, A. Carboxyl methylcellulose (CMC) containing moringa plant extracts as new postharvest organic edible coating for Avocado (Persea americana Mill.) fruit. Sci. Hortic. 2017, 226, 201-207. [CrossRef]

40. de Jesús Salas-Méndez, E.; Vicente, A.; Pinheiro, A.C.; Ballesteros, L.F.; Silva, P.; Rodríguez-García, R.; Hernández-Castillo, F.D.; Díaz-Jiménez, M.d.L.V.; Flores-López, M.L.; Villarreal-Quintanilla, J.Á. Application of edible nanolaminate coatings with antimicrobial extract of Flourensia cernua to extend the shelf-life of tomato (Solanum lycopersicum L.) fruit. Postharvest Biol. Technol. 2019, 150, 19-27. [CrossRef]

41. Marín, A.; Plotto, A.; Atarés, L.; Chiralt, A. Lactic acid bacteria incorporated into edible coatings to control fungal growth and maintain postharvest quality of grapes. HortScience 2019, 54, 337-343. [CrossRef]

42. Kharchoufi, S.; Parafati, L.; Licciardello, F.; Muratore, G.; Hamdi, M.; Cirvilleri, G.; Restuccia, C. Edible coatings incorporating pomegranate peel extract and biocontrol yeast to reduce Penicillium digitatum postharvest decay of oranges. Food Microbiol. 2018, 74, 107-112. [CrossRef]

43. Ghidelli, C.; Pérez-Gago, M. Recent advances in modified atmosphere packaging and edible coatings to maintain quality of fresh-cut fruits and vegetables. Crit. Rev. Food Sci. Nutr. 2018, 58, 662-679. [CrossRef] [PubMed]

44. Marín, A.; Baldwin, E.A.; Bai, J.; Wood, D.; Ference, C.; Sun, X.; Brecht, J.K.; Plotto, A. Edible coatings as carriers of antibrowning compounds to maintain appealing appearance of fresh-cut mango. HortTechnology 2021, 31, 27-35. [CrossRef]

45. Suhag, R.; Kumar, N.; Petkoska, A.T.; Upadhyay, A. Film formation and deposition methods of edible coating on food products: A review. Food Res. Int. 2020, 136, 109582. [CrossRef]

46. Senturk Parreidt, T.; Schmid, M.; Müller, K. Effect of dipping and vacuum impregnation coating techniques with alginate based coating on physical quality parameters of cantaloupe melon. J. Food Sci. 2018, 83, 929-936. [CrossRef] [PubMed]

47. Valdés, A.; Ramos, M.; Beltrán, A.; Jiménez, A.; Garrigós, M.C. State of the art of antimicrobial edible coatings for food packaging applications. Coatings 2017, 7, 56. [CrossRef]

48. Tahir, H.E.; Xiaobo, Z.; Mahunu, G.K.; Arslan, M.; Abdalhai, M.; Zhihua, L. Recent developments in gum edible coating applications for fruits and vegetables preservation: A review. Carbohydr. Polym. 2019, 224, 115141. [CrossRef] [PubMed]

49. Dhanapal, A.; Sasikala, P.; Rajamani, L.; Kavitha, V.; Yazhini, G.; Banu, M.S. Edible films from polysaccharides. Food Sci. Qual. Manag. 2012, 3, 9.

50. Atieno, L.; Owino, W.; Ateka, E.M.; Ambuko, J. Influence of coating application methods on the postharvest quality of cassava Int. J. Food Sci. 2019, 2019, 2148914. [CrossRef] [PubMed]

51. Nile, S.H.; Baskar, V.; Selvaraj, D.; Nile, A.; Xiao, J.; Kai, G. Nanotechnologies in food science: Applications, recent trends, and future perspectives. Nano-Micro Lett. 2020, 12, 1-34. [CrossRef] [PubMed]

52. Zambrano-Zaragoza, M.L.; González-Reza, R.; Mendoza-Muñoz, N.; Miranda-Linares, V.; Bernal-Couoh, T.F.; Mendoza-Elvira, S.; Quintanar-Guerrero, D. Nanosystems in edible coatings: A novel strategy for food preservation. Int. J. Mol. Sci. 2018, 19, 705. [CrossRef]

53. Liu, R.; Liu, D.; Liu, Y.; Song, Y.; Wu, T.; Zhang, M. Using soy protein SiOx nanocomposite film coating to extend the shelf life of apple fruit. Int. J. Food Sci. Technol. 2017, 52, 2018-2030. [CrossRef]

54. McClements, D.J. Advances in edible nanoemulsions: Digestion, bioavailability, and potential toxicity. Prog. Lipid Res. 2020, 101081.

55. Kumar, S.; Mukherjee, A.; Dutta, J. Chitosan based nanocomposite films and coatings: Emerging antimicrobial food packaging alternatives. Trends Food Sci. Technol. 2020, 97, 196-209. [CrossRef]

56. McClements, D.J. Edible nanoemulsions: Fabrication, properties, and functional performance. Soft Matter 2011, 7, 2297-2316. [CrossRef]

57. McClements, D.J.; Rao, J. Food-grade nanoemulsions: Formulation, fabrication, properties, performance, biological fate, and potential toxicity. Crit. Rev. Food Sci. Nutr. 2011, 51, 285-330. [CrossRef]

58. Zhang, R.; Zhang, Z.; McClements, D.J. Nanoemulsions: An emerging platform for increasing the efficacy of nutraceuticals in foods. Colloids Surf. B Biointerfaces 2020, 194, 111202. [CrossRef]

59. Salvia-Trujillo, L.; Rojas-Graü, M.A.; Soliva-Fortuny, R.; Martín-Belloso, O. Use of antimicrobial nanoemulsions as edible coatings: Impact on safety and quality attributes of fresh-cut Fuji apples. Postharvest Biol. Technol. 2015, 105, 8-16. [CrossRef]

60. Prakash, A.; Baskaran, R.; Vadivel, V. Citral nanoemulsion incorporated edible coating to extend the shelf life of fresh cut pineapples. LWT 2020, 118, 108851. [CrossRef]

61. Zhang, Z.; Zhang, R.; McClements, D.J. Encapsulation of $\beta$-carotene in alginate-based hydrogel beads: Impact on physicochemical stability and bioaccessibility. Food Hydrocoll. 2016, 61, 1-10. [CrossRef]

62. McClements, D.J. Food Emulsions: Principles, Practices, and Techniques; CRC Press: Boca Raton, FL, USA, 2015.

63. Queste, S.; Salager, J.; Strey, R.; Aubry, J. The EACN scale for oil classification revisited thanks to fish diagrams. J. Colloid Interface Sci. 2007, 312, 98-107. [CrossRef] [PubMed]

64. Blomberg, E.; Claesson, P.M. Surface forces and emulsion stability: Chapter 7. In Food Emulsions; Friberg, S.E., Larsson, K., Sjöblom, J., Eds.; CRC Press: New York, NY, USA, 2004; pp. 254-297. 
65. Yao, K.; McClements, D.J.; Xiang, J.; Zhang, Z.; Cao, Y.; Xiao, H.; Liu, X. Improvement of carotenoid bioaccessibility from spinach by co-ingesting with excipient nanoemulsions: Impact of the oil phase composition. Food Funct. 2019, 10, 5302-5311. [CrossRef]

66. Salvia-Trujillo, L.; Martín-Belloso, O.; McClements, D.J. Excipient nanoemulsions for improving oral bioavailability of bioactives. Nanomaterials 2016, 6, 17. [CrossRef] [PubMed]

67. Tripathi, A.D.; Sharma, R.; Agarwal, A.; Haleem, D.R. Nanoemulsions based edible coatings with potential food applications. Int. J. Biobased Plast. 2021, 3, 112-125. [CrossRef]

68. Acevedo-Fani, A.; Soliva-Fortuny, R.; Martín-Belloso, O. Nanostructured emulsions and nanolaminates for delivery of active ingredients: Improving food safety and functionality. Trends Food Sci. Technol. 2017, 60, 12-22. [CrossRef]

69. Pilon, L.; Spricigo, P.C.; Miranda, M.; de Moura, M.R.; Assis, O.B.G.; Mattoso, L.H.C.; Ferreira, M.D. Chitosan nanoparticle coatings reduce microbial growth on fresh-cut apples while not affecting quality attributes. Int. J. Food Sci. Technol. 2015, 50, 440-448. [CrossRef]

70. Atarés, L.; Chiralt, A. Essential oils as additives in biodegradable films and coatings for active food packaging. Trends Food Sci. Technol. 2016, 48, 51-62. [CrossRef]

71. Maisanaba, S.; Llana-Ruiz-Cabello, M.; Gutiérrez-Praena, D.; Pichardo, S.; Puerto, M.; Prieto, A.; Jos, A.; Cameán, A. New advances in active packaging incorporated with essential oils or their main components for food preservation. Food Rev. Int. 2017, 33, 447-515. [CrossRef]

72. Sessa, M.; Ferrari, G.; Donsì, F. Novel edible coating containing essential oil nanoemulsions to prolong the shelf life of vegetable products. Chem. Eng. Trans. 2015, 43, 55-60.

73. Severino, R.; Ferrari, G.; Vu, K.D.; Donsì, F.; Salmieri, S.; Lacroix, M. Antimicrobial effects of modified chitosan based coating containing nanoemulsion of essential oils, modified atmosphere packaging and gamma irradiation against Escherichia coli O157: H7 and Salmonella Typhimurium on green beans. Food Control 2015, 50, 215-222. [CrossRef]

74. Gundewadi, G.; Rudra, S.G.; Sarkar, D.J.; Singh, D. Nanoemulsion based alginate organic coating for shelf life extension of okra. Food Packag. Shelf Life 2018, 18, 1-12. [CrossRef]

75. Chu, Y.; Gao, C.; Liu, X.; Zhang, N.; Xu, T.; Feng, X.; Yang, Y.; Shen, X.; Tang, X. Improvement of storage quality of strawberries by pullulan coatings incorporated with cinnamon essential oil nanoemulsion. LWT 2020, 122, 109054. [CrossRef]

76. Kim, I.H.; Lee, H.; Kim, J.E.; Song, K.B.; Lee, Y.S.; Chung, D.S.; Min, S.C. Plum coatings of lemongrass oil-incorporating carnauba wax-based nanoemulsion. J. Food Sci. 2013, 78, E1551-E1559. [CrossRef]

77. Kim, I.-H.; Oh, Y.A.; Lee, H.; Song, K.B.; Min, S.C. Grape berry coatings of lemongrass oil-incorporating nanoemulsion. LWT-Food Sci. Technol. 2014, 58, 1-10. [CrossRef]

78. De León-Zapata, M.A.; Pastrana-Castro, L.; Barbosa-Pereira, L.; Rua-Rodríguez, M.L.; Saucedo, S.; Ventura-Sobrevilla, J.M.; Salinas-Jasso, T.A.; Rodríguez-Herrera, R.; Aguilar, C.N. Nanocoating with extract of tarbush to retard Fuji apples senescence. Postharvest Biol. Technol. 2017, 134, 67-75. [CrossRef]

79. Robledo, N.; López, L.; Bunger, A.; Tapia, C.; Abugoch, L. Effects of antimicrobial edible coating of thymol nanoemulsion/quinoa protein/chitosan on the safety, sensorial properties, and quality of refrigerated strawberries (Fragaria $\times$ ananassa) under commercial storage environment. Food Bioprocess Technol. 2018, 11, 1566-1574. [CrossRef]

80. Deng, Z.; Jung, J.; Simonsen, J.; Wang, Y.; Zhao, Y. Cellulose nanocrystal reinforced chitosan coatings for improving the storability of postharvest pears under both ambient and cold storages. J. Food Sci. 2017, 82, 453-462. [CrossRef]

81. Kumar, R. Health effects of morpholine based coating for fruits and vegetables. Int. J. Med. Res. Health Sci. 2016, 5, 32-38.

82. Kumar, R.; Kapur, S. Morpholine: A glazing agent for fruits and vegetables coating/waxing. Int. J. Sci. Technol. Eng. 2016, 2, 694-697.

83. Ohnishi, T. Studies on mutagenicity of the food additive morpholine (fatty acid salt). Nippon Eiseigaku Zasshi Jpn. J. Hyg. 1984, 39, 729-748. [CrossRef]

84. Mirvish, S.; Salmasi, S.; Cohen, S.; Patil, K.; Mahboubi, E. Liver and forestomach tumors and other forestomach lesions in rats treated with morpholine and sodium nitrite, with and without sodium ascorbate. J. Natl. Cancer Inst. 1983, 71, 81-85.

85. Health Canada. ARCHIVED-A Summary of the Health Hazard Assessment of Morpholine in Wax Coatings of Apples. Available online: https://www.canada.ca/en/health-canada/services/food-nutrition/food-safety/information-product/summaryhealth-hazard-assessment-morpholine-coatings-apples.html (accessed on 29 September 2021).

86. Hagenmaier, R.D.; Baker, R.A. Edible coatings from morpholine-free wax microemulsions. J. Agric. Food Chem. 1997, 45, 349-352. [CrossRef]

87. Ncama, K.; Magwaza, L.; Mditshwa, A.; Tesfay, S. Plant-based edible coatings for managing postharvest quality of fresh horticultural produce: A review. Food Packag. Shelf Life 2018, 16, 157-167. [CrossRef]

88. Donsì, F.; Annunziata, M.; Sessa, M.; Ferrari, G. Nanoencapsulation of essential oils to enhance their antimicrobial activity in foods. LWT-Food Sci. Technol. 2011, 44, 1908-1914. [CrossRef]

89. De Oliveira Filho, J.; Albiero, B.; Cipriano, L.; Bezerra, C.d.O.; Oldoni, F.; Egea, M.; de Azeredo, H.; Ferreira, M. Arrowroot starch-based films incorporated with a carnauba wax nanoemulsion, cellulose nanocrystals, and essential oils: A new functional material for food packaging applications. Cellulose 2021, 28, 6499-6511. [CrossRef]

90. Qi, W.; Li, T.; Zhang, Z.; Wu, T. Preparation and characterization of oleogel-in-water pickering emulsions stabilized by cellulose nanocrystals. Food Hydrocoll. 2021, 110, 106206. [CrossRef]

91. Chutia, H.; Mahanta, C. Properties of starch nanoparticle obtained by ultrasonication and high pressure homogenization for developing carotenoids-enriched powder and Pickering nanoemulsion. Innov. Food Sci. Emerg. Technol. 2021, 74, 102822. [CrossRef] 
92. Nandy, M.; Lahiri, B.; Philip, J. Inter-droplet force between magnetically polarizable Pickering oil-in-water nanoemulsions stabilized with $\gamma$-Al2O3 nanoparticles: Role of electrostatic and electric dipolar interactions. J. Colloid Interface Sci. 2021, 607, 1671-1686. [CrossRef]

93. Xiao, Z.; Liu, Y.; Niu, Y.; Kou, X. Cyclodextrin supermolecules as excellent stabilizers for Pickering nanoemulsions. Colloids Surf. A Physicochem. Eng. Asp. 2020, 588, 124367. [CrossRef]

94. Bao, Y.; Zhang, Y.; Liu, P.; Ma, J.; Zhang, W.; Liu, C.; Simion, D. Novel fabrication of stable Pickering emulsion and latex by hollow silica nanoparticles. J. Colloid Interface Sci. 2019, 553, 83-90. [CrossRef] [PubMed]

95. Almasi, H.; Azizi, S.; Amjadi, S. Development and characterization of pectin films activated by nanoemulsion and Pickering emulsion stabilized marjoram (Origanum majorana L.) essential oil. Food Hydrocoll. 2020, 99, 105338. [CrossRef]

96. López-Monterrubio, D.; Lobato-Calleros, C.; Vernon-Carter, E.; Alvarez-Ramirez, J. Influence of $\beta$-carotene concentration on the physicochemical properties, degradation and antioxidant activity of nanoemulsions stabilized by whey protein hydrolyzate-pectin soluble complexes. LWT 2021, 143, 111148. [CrossRef]

97. Wani, T.; Masoodi, F.; Jafari, S.M.; McClements, D. Safety of nanoemulsions and their regulatory status. In Nanoemulsions; Jafari, S.M., McClements, D.J., Eds.; Elsevier: Amsterdam, The Netherlands, 2018; pp. 613-628.

98. McClements, D.; Xiao, H. Potential biological fate of ingested nanoemulsions: Influence of particle characteristics. Food Funct. 2012, 3, 202-220. [CrossRef]

99. Kaur, K.; Kumar, R.; Goel, S.; Uppal, S.; Bhatia, A.; Mehta, S. Physiochemical and cytotoxicity study of TPGS stabilized nanoemulsion designed by ultrasonication method. Ultrason. Sonochem. 2017, 34, 173-182. [CrossRef]

100. Marchese, E.; D'onofrio, N.; Balestrieri, M.; Castaldo, D.; Ferrari, G.; Donsì, F. Bergamot essential oil nanoemulsions: Antimicrobial and cytotoxic activity. Z. Nat. C 2020, 75, 279-290. [CrossRef] [PubMed]

101. Hort, M.; Alves, B.d.S.; Ramires Junior, O.; Falkembach, M.; Araújo, G.d.M.; Fernandes, C.; Tavella, R.; Bidone, J.; Dora, C.; da Silva Júnior, F. In vivo toxicity evaluation of nanoemulsions for drug delivery. Drug Chem. Toxicol. 2021, 44, 585-594. [CrossRef]

102. Donsì, F;; Ferrari, G. Essential oil nanoemulsions as antimicrobial agents in food. J. Biotechnol. 2016, 233, 106-120. [CrossRef] [PubMed]

103. Amenta, V.; Aschberger, K.; Arena, M.; Bouwmeester, H.; Moniz, F.; Brandhoff, P.; Gottardo, S.; Marvin, H.; Mech, A.; Pesudo, L. Regulatory aspects of nanotechnology in the agri/feed/food sector in EU and non-EU countries. Regul. Toxicol. Pharmacol. 2015, 73, 463-476. [CrossRef] [PubMed] 